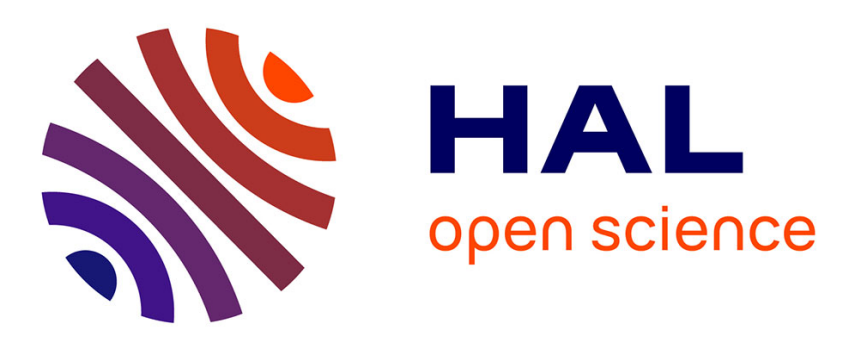

\title{
3D modelling of electromagnetic fields in local hyperthermia
}

Nicolas Siauve, Laurent Nicolas, Christian Vollaire, Christian Marchal

\section{To cite this version:}

Nicolas Siauve, Laurent Nicolas, Christian Vollaire, Christian Marchal. 3D modelling of electromagnetic fields in local hyperthermia. European Physical Journal: Applied Physics, 2003, 21 (3), pp.243-250. 10.1051/epjap:2003008 . hal-00140439

\section{HAL Id: hal-00140439 \\ https://hal.science/hal-00140439}

Submitted on 18 Apr 2007

HAL is a multi-disciplinary open access archive for the deposit and dissemination of scientific research documents, whether they are published or not. The documents may come from teaching and research institutions in France or abroad, or from public or private research centers.
L'archive ouverte pluridisciplinaire HAL, est destinée au dépôt et à la diffusion de documents scientifiques de niveau recherche, publiés ou non, émanant des établissements d'enseignement et de recherche français ou étrangers, des laboratoires publics ou privés. 


\title{
3D modelling of electromagnetic fields in local hyperthermia
}

\author{
N. Siauve ${ }^{1}$, L. Nicolas ${ }^{1}$, C. Vollaire ${ }^{1}$, and C. Marchal $^{2}$ \\ ${ }^{1}$ CEGELY, UMR CNRS 5005, Ecole Centrale de Lyon, BP163, 69131 Ecully cedex, France \\ ${ }^{2}$ Unité d'Hyperthermie, Centre Alexis Vautrin, 54511 Vandoeuvre les Nancy, France \\ e-mail: nicolas.siauve a eea.ec-lyon.fr
}

\begin{abstract}
This paper describes a 3D finite element formulation used for radiofrequency hyperthermia problems. Edge finite elements have been coupled with an absorbing boundary condition. Results are presented in term of specific absorption rate. They are compared to experimental measurements performed on a phantom having equivalent electromagnetic properties to human tissues. This comparison shows a good agreement between both numerical and experimental results. Simulations are also achieved on a heterogeneous phantom. The model is then used on a real geometry coming from computerized tomography scans.
\end{abstract}

PACS. 02.70.Dh Finite-element and Galerkin methods - 41.20.Jb Electromagnetic wave propagation; radiowave propagation $-87.50 . \mathrm{Rr}$ Electric fields

\section{Introduction}

Local hyperthermia is used as adjuvant therapy in oncology treatment. It can be used alone or together with chemotherapy or radiotherapy to increase their effects $[1,2]$. The purpose of Radiofrequencies (RF) hyperthermia is to heat $\left(42-44^{\circ} \mathrm{C}\right)$ a localised cancerous tumour without overheating the surrounding normal tissue. The effective temperature range of local hyperthermia is very small. At temperatures lower than $42^{\circ} \mathrm{C}$, there is no effect. At temperatures higher than $44^{\circ} \mathrm{C}$, normal cells around the tumour are damaged [3]. This elevation of temperature is obtained by submitting locally the patient to a radiofrequency electromagnetic field using external applicators. The space between the patient and the applicator is filled by a pocket of water, called bolus, in order to avoid an excessive heating at the skin level. The operating frequency of the applicators varies accordingly to the depth where the tumour to reach is located. Two RF (13.56 and $27.12 \mathrm{MHz}$ ) are used for heat deep-seated tumours located at $90 \mathrm{~mm}$ below the skin surface [3].

All the success of this technique lies in the good focalization of the heat, which is actually related to the electromagnetic field, inside the cancerous tumour. Furthermore, it is required to avoid the overheating in close organs [4]. It is therefore essential to know with accuracy the electromagnetic fields distribution. The absorption of energy in a medium is represented by the Specific Absorption Rate (SAR), which is the main element in the distribution of temperature [5]

The SAR distribution within the patient is governed by the interaction of the irradiated electric field and the patient tissues. This interaction is rather complex due to the inhomogeneous dielectric properties of these tissues. As consequence, determination of the excitation amplitudes and phases for optimal tumour heating on the basis of intuition is a difficult issue and cannot be done solely by intuition [6]. Furthermore the SAR distribution is difficulty measurable in the patient during hyperthermia treatment [7]. For these two reasons, it is then necessary to model this SAR distribution.

To determine numerically the electric field distribution for hyperthermia problems, the principal methods used are the Finite Difference Time Domain (FDTD) technique and the Finite Element (FE) method. The FDTD technique allows to modelize heterogeneous electromagnetic problem, and it is simple to implement. It has already been used for hyperthermia calculation $[8,9]$, and it has been shown to be well suited for the design of new hyperthermia applicator $[10,11]$. However, it deals with cubic elements which are not really appropriate to modelize with accuracy the curved interfaces such as those found in human bodies [12]. On another hand, the FE method has also proved its capability of modelling heterogeneous structures. Furthermore, it allows to handle with irregular structures through the utilization of tetrahedral elements. That is the reason why we have chosen the FE method. Some FE methods have already been used for microwave heating modelling. In [13] a 2D model was studied for hyperthermia. In [14] a 3D case has been solved for the microwave heating of a lossy dielectric sphere. In this paper, the FE method is applied to a realistic clinical problem.

Our main objective is to develop a method, based on the 3D numerical modelling of electromagnetic phenomena in the human body, in order to optimize the treatment of deepseated cancerous tumours. This paper is the first step of a complete study. The FE formulation developed for such a purpose is first presented. The experimental procedure used for validation is then described. Computed SAR is then compared to measured results. In the last section the model is 
used on real geometry stemming from Computerized Tomography (CT) scans.

\section{The finite element formulation}

The vector wave equation is written in term of electric field:

$$
\nabla \times \frac{1}{\mu_{r}} \nabla \times \mathbf{E}-k_{0}^{2} \varepsilon_{r} \mathbf{E}=-j \omega \mu_{0} \mathbf{J}
$$

With $k_{0}=\omega \sqrt{\mu_{0} \varepsilon_{0}}$ the constant of the propagation of the electromagnetic field and $\mathrm{J}\left(\mathrm{A} / \mathrm{m}^{2}\right)$ the density of the electric current. $\mu_{\mathrm{r}}$ is the permeability and $\varepsilon_{\mathrm{r}}$ is the complex permittivity defined by introducing the conductivity $\sigma[15]$ :

$$
\begin{aligned}
& \varepsilon=\varepsilon_{r} \varepsilon_{0}=\left(\varepsilon_{\text {real }}-j \varepsilon_{\text {imag }}\right) \varepsilon_{0} \\
& \text { with } \quad \varepsilon_{\text {imag }}=\frac{\sigma}{\omega}
\end{aligned}
$$

By applying the Galerkin weighted residual method, the following expression is obtained:

$$
\int_{v} W\left[\nabla \times \frac{1}{\mu_{r}} \nabla \times \mathbf{E}-k_{0}^{2} \varepsilon_{r} \mathbf{E}\right] . d v=-j \omega \mu_{0} \int_{v} W \mathbf{J} . d v
$$

Where $\mathrm{W}$ is the weight function.

By using the vectorial identity (5) and the Stokes theorem (6).

$$
\begin{aligned}
& W \nabla \times \nabla \times \mathbf{E}=\nabla \times(W \nabla \times \mathbf{E})-\nabla W \times \nabla \times \mathbf{E} \\
& \int_{v} \nabla \times W \frac{1}{\mu_{r}} \nabla \times \mathbf{E} . d v=\int_{s} n \times W \frac{1}{\mu_{r}} \nabla \times \mathbf{E} . d s
\end{aligned}
$$

The time harmonic FE formulation is then obtained (7):

$$
\begin{aligned}
& -\int_{v} \nabla W \times \frac{1}{\mu_{r}} \nabla \times \mathbf{E} . d v-\int_{v} W k_{0}^{2} \varepsilon_{r} \mathbf{E} . d v+\int_{s_{e x t}} n \times(W \nabla \times \mathbf{E}) . d s \\
& =-j \omega \mu_{0} \int_{\Gamma} W \mathbf{J} . d v
\end{aligned}
$$

Although the frequency is low $(27.12 \mathrm{MHz})$, we cannot ignore the displacement current according to the permittivity values of the human tissues.

In order to take into account the wave propagation through the FE domain, the FE formulation is coupled with a first order vector Engquist Majda Absorbing Boundary Conditions (ABC) [16]. The external boundary is then a parallelepiped box, located close to the device. Only first order vector $\mathrm{ABC}$ is used because the $\mathrm{FE}$ formulation is based on first order tetrahedral elements. Due to the electromagnetic skin depth values in the human tissues at the considered frequency, only a minimal part of the field comes out from the body. The spurious reflections on the external boundary remain then small and do not have a great influence on the fields inside the human body. The first order vector
Engquist Majda can actually be identified to the SilverMüller condition:

$$
n \times \nabla \times \mathbf{E} \cong g_{A B C}(\mathbf{E})=j k_{0} \mathbf{E}_{t}
$$

With $\mathbf{E}_{t}$ the tangential electric field.

The discretization is obtained by using classical Nédélec edge elements [17], since they ensure the continuity of tangential field components across interface between different media [18]. Tetrahedral elements are used since they fit on complex geometries such as the human bodies or complex applicators.

The matrix is sparse and symmetric. In order to solve it, an iterative method is used: conjugate gradient solver with several preconditioning techniques. This algorithm is more advantageous than direct method for both CPU times and memory occupation reasons [19].

The SAR is linked to the electric field and to the conductivity and the density of tissues (9).

$$
S A R=\frac{\sigma E_{\max }^{2}}{2 \rho} \quad(\mathrm{W} / \mathrm{kg})
$$

Where $E_{\max }$ is the module of the complex electric field, $\sigma$ the electrical conductivity $(\mathrm{S} / \mathrm{m})$ and $\rho$ the mass density $\left(\mathrm{kg} / \mathrm{m}^{3}\right)$ with respect to the different media.

\section{Validation of the 3D model}

The calculation code has been validated on a system of deep hyperthermia (tumours situated at $100 \mathrm{~mm}$ under the skin).

\subsection{Experimental device}

This device is made of a phantom and an applicator, which is actually a waveguide (Fig. 1). The field is generated by a dipole antenna $(5 \mathrm{~mm})$ located in the applicator, operating at 27.12 MHz (Fig. 1.a). The waveguide is filled with conducting water. The phantom is made of a vat in plexiglass containing polyacrilamide gel (Fig. 1.c) whose electromagnetic properties are close to that of the muscle tissue.

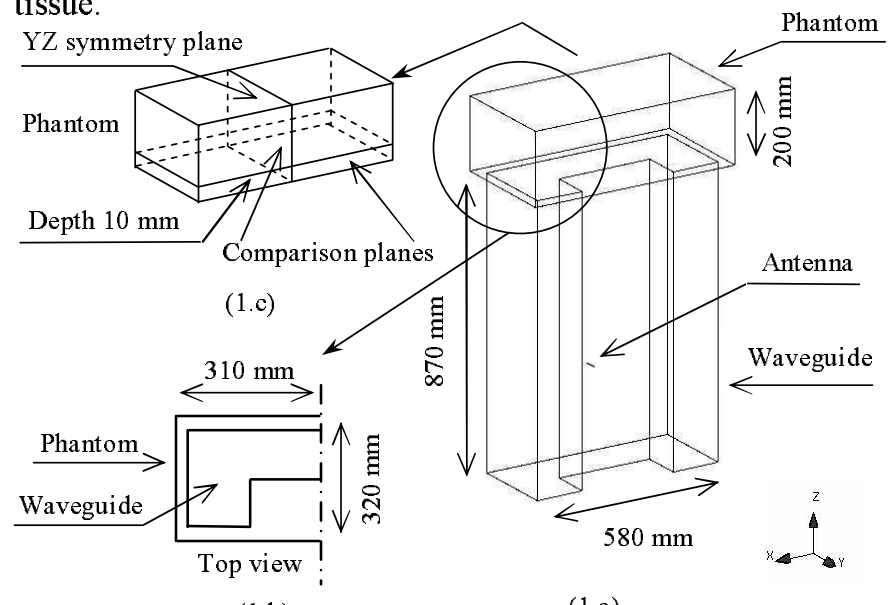

(1.b)

(1.a)

Fig. 1. Geometry of the experimental device. 
Electromagnetic properties of the different media are given in Table 1 .

The experimental SAR distribution inside the phantom is obtained by an indirect method. It has been shown that, in a first approximation, the SAR distribution may be directly related to the temperature distribution [20]. The temperature in the phantom is then measured with twelve optical fiber temperature detectors [21].

\subsection{Electromagnetic and computational characteristics}

The geometry is meshed with 40 to 50 nodes per wavelength [22]. Such a thin mesh density is required in the phantom in order to ensure the convergence of the solver to a correct solution. The mesh is made of 104165 tetrahedral elements and 20337 nodes, leading to 130268 degrees of freedom. Electromagnetic properties and mesh densities are presented in Table 1.

\begin{tabular}{llll}
\hline & Phantom & Water & Plexiglass \\
\hline Permittivity (real part $\left.\varepsilon_{\text {real }}\right)$ & 82.16 & 72.5 & 2.5 \\
Permittivity (imaginary part $\varepsilon_{\text {imag }}$ ) & 431.4 & 1.327 & 0 \\
Permeability & 1 & 1 & 1 \\
Conductivity $\sigma(\mathrm{S} / \mathrm{m})$ & 0.65 & 0.002 & 0 \\
Density $\rho\left(\mathrm{kg} / \mathrm{m}^{3}\right)$ & 1030 & 1000 & 1300 \\
Wavelength $\lambda(\mathrm{m})$ & 0.685 & 1.30 & 7.00 \\
Electromagnetic skin depth $\delta(\mathrm{m})$ & 0.132 & 22.59 & - \\
Mesh density $($ nodes $/ \lambda)$ & 53 & 54 & 540 \\
\hline
\end{tabular}

Table 1. Electromagnetic properties and mesh density of the different media.

The values of the wavelength $\lambda$ and the electromagnetic skin depth $\delta$ in lossy media are given by (10) and (11) [15].

$$
\begin{gathered}
\lambda=\frac{2 \pi}{\omega \sqrt{\mu_{r} \mu_{0} \varepsilon_{\text {real }} \varepsilon_{0}}\left\{\frac{1}{2}\left[\sqrt{1+\left(\frac{\sigma}{\omega \varepsilon_{\text {real }} \varepsilon_{0}}\right)^{2}}+1\right]\right\}^{\frac{1}{2}}} \\
\delta=\frac{1}{\omega \sqrt{\mu_{r} \mu_{0} \varepsilon_{\text {real }} \varepsilon_{0}}\left\{\frac{1}{2}\left[\sqrt{1+\left(\frac{\sigma}{\omega \varepsilon_{\text {real }} \varepsilon_{0}}\right)^{2}}-1\right]\right\}^{\frac{1}{2}}}
\end{gathered}
$$

The $\mathrm{ABC}$ is set at $50 \mathrm{~mm}$ of the device. The antenna in the waveguide is modelled by a current density fixed on an edge. Only the half of the geometry is described, due to the YZ symmetry plane (Fig. 1.b).

Preliminary numerical experiences have shown that the mesh density has to be equal to 20 nodes per wavelength for dielectric problem. For dielectric materials with losses (complex value of the permittivity), the mesh density has to be about 40 nodes per wavelength. These mesh densities warranted the convergence of the iterative algorithm used to solve the matrix system.

Table 2 shows the number of iterations and the CPU times used to solve the matrix system with the conjugate gradient written with different preconditioning method: diagonal, Symmetric Successive Over Relaxation (SSOR) and incomplete Cholesky. Computations have been performed on a HP station J5000 (PA risk 8500 processor with 1 Go of RAM). It is shown that the SSOR preconditioning leads to the lower CPU times.

Table 2. Number of iterations and CPU times.

\subsection{Computational results}

\begin{tabular}{lcc}
\hline Preconditioning & Number of iterations & CPU time (s) \\
\hline Diagonal & 129219 & 184257 \\
SSOR & 39601 & 106996 \\
Cholesky (direct identification) & 75507 & 227186 \\
Cholesky (Gauss algorithm) & 125687 & 333465 \\
\hline
\end{tabular}

Figure 2.a shows the 3D SAR distribution on the half of the phantom and figure 2.b represents this SAR distribution on the $\mathrm{xOz}$ plane.

Fig. 2. SAR distribution on the phantom (2.a) and on the $\mathrm{xOz}$ plane (2.b).
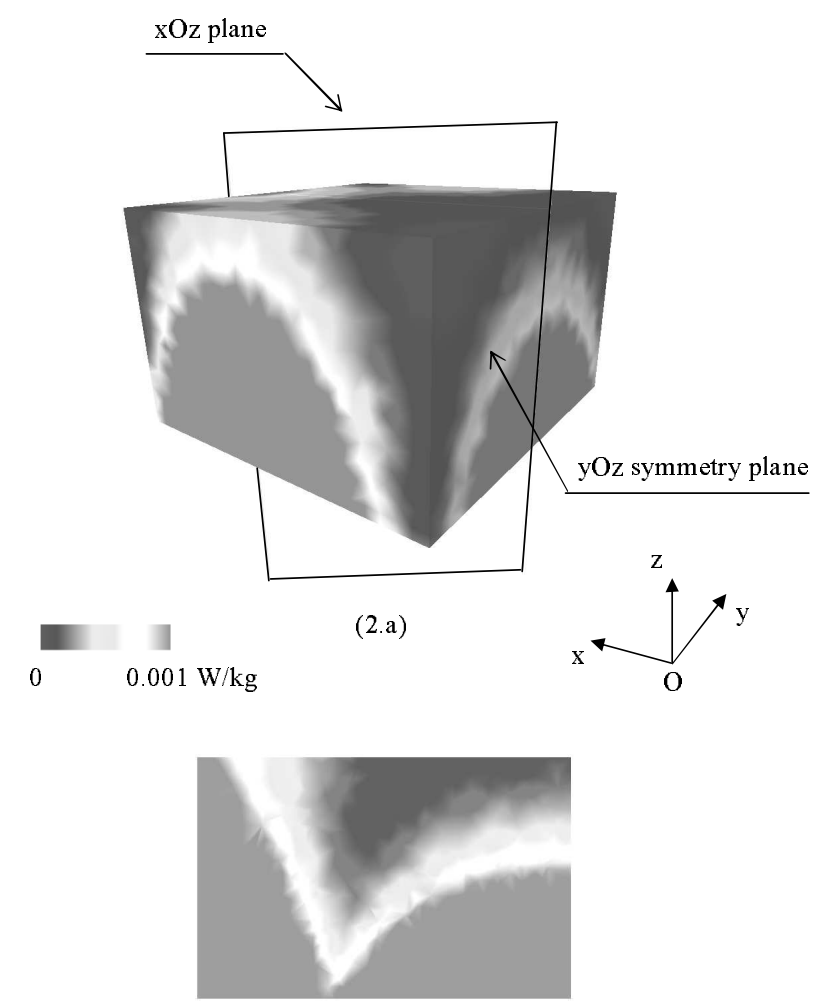

(2.b)

3.4 Comparison of computational results with measurements on a homogenous phantom 
Figure 3 shows the normalized SAR distribution in the $y O z$ symmetry plane. Figure 4 shows the normalized SAR distribution at $10 \mathrm{~mm}$ depth in the phantom in the $\mathrm{xOy}$ plane. Normalized SAR is obtained by comparison with the maximum value of the SAR in the phantom (12).

$$
\text { NormalizedSAR }=\frac{S A R}{\text { MaximumSAR }}
$$
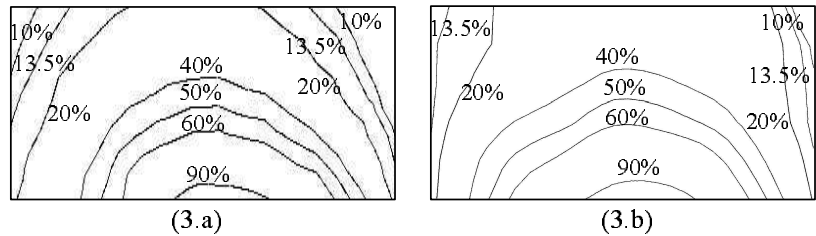

(3.b)
Fig. 3. Comparison of calculated SAR distribution (3.a) and temperature measurements (3.b) in the $\mathrm{yOz}$ symmetry plane.

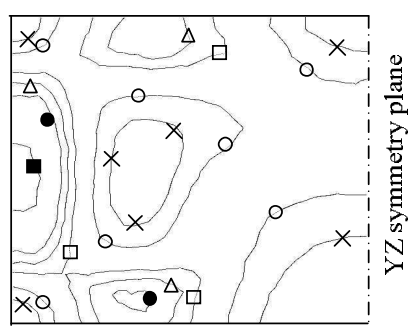

(4.a)

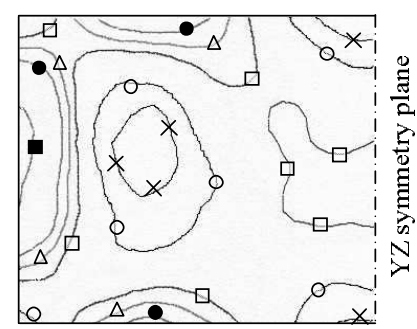

(4.b)

$\times \quad 10 \% \quad \square \quad 40 \%$

- $60 \%$

○ $20 \% \quad \Delta \quad 50 \%$

- $90 \%$

Fig. 4. Comparison of calculated SAR distribution (4.a) and temperature measurements (4.b) in the xOy plane.

Both numerical and experimental results are in good agreement. Slight differences may be explained by the presence of the $0.8 \mathrm{~mm}$ diameter catheters used for the temperature measurements. These catheters are filled out with air. They are actually not modelized numerically. The experimental methodology (temperature measurement instead of field measurement) may also have some impact on the results.

\subsection{Calculated SAR distribution in a heterogeneous phantom}

As an example, Figure 5 shows the ability of the formulation to handle with several biological media (bone, blood, tumour and phantom). The electromagnetic properties of this different media are given in the Table 3 [23,24].

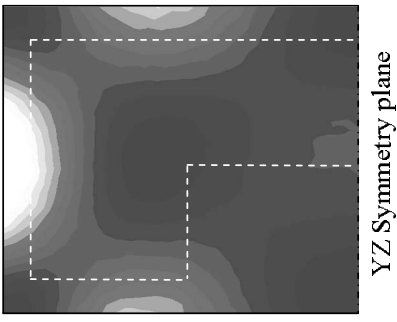

(5.a)

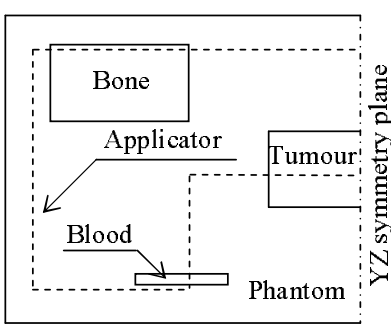

(5.b)

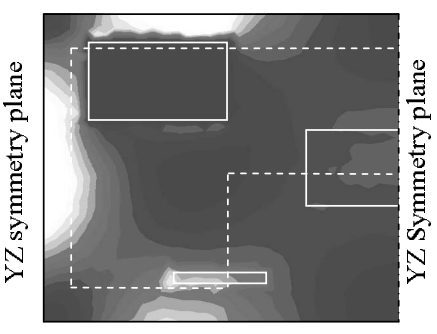

(5.c)
Fig. 5. Calculated SAR distribution in a homogeneous phantom (5.a) and in a heterogeneous phantom (5.c) with several biological media (5.b).

Table 3. Electromagnetic properties and mesh density of the different media

\begin{tabular}{lllll}
\hline & Phantom & Tumour & Bone & Blood \\
\hline Permittivity (real part $\left.\varepsilon_{\text {real }}\right)$ & 82.16 & 60 & 7.3 & 118 \\
Permittivity (imaginary part $\left.\varepsilon_{\text {imag }}\right)$ & 431.4 & 531 & 19.9 & 730 \\
Permeability & 1 & 1 & 1 & 1 \\
Conductivity $\sigma(\mathrm{S} / \mathrm{m})$ & 0.645 & 0.8 & 0.03 & 1.1 \\
Density $\rho\left(\mathrm{kg} / \mathrm{m}^{3}\right)$ & 1030 & 1177 & 1810 & 1060 \\
Wavelength $\lambda(\mathrm{m})$ & 0.685 & 0.642 & 2.93 & 0.534 \\
Electromagnetic skin depth $\delta(\mathrm{m})$ & 0.132 & 0.114 & 0.67 & 0.100 \\
Mesh density $($ nodes $/ \lambda)$ & 53 & 49 & 225 & 41 \\
\hline
\end{tabular}

In this study, same geometry and mesh density for both homogeneous and heterogeneous structures are used. Only the properties of the media are modified. For the homogeneous phantom, the inclusions are filled with the same properties than the phantom.

The difference between homogeneous and heterogeneous phantom comes from the values of the parameters (conductivity, permittivity and density). The density has an important part on the SAR distribution. 
To solve this matrix system the conjugate gradient solver with SSOR preconditioning is also used. The number of iterations and the CPU times are presented in the Table 4 . We can see the baneful influence of the presence of several media, which decrease the efficiency of the solver while the degrees of freedom is the same.

Table 4. Number of iterations and CPU times

\begin{tabular}{lcc}
\hline $\begin{array}{l}\text { Structure of } \\
\text { the phantom }\end{array}$ & $\begin{array}{c}\text { Number of } \\
\text { iterations }\end{array}$ & $\begin{array}{c}\text { CPU Times } \\
\text { (seconds) }\end{array}$ \\
\hline Homogeneous & 41816 & 130684 \\
Heterogeneous & 48217 & 149883 \\
\hline
\end{tabular}

\section{Utilisation of the $3 D$ model on real human organs meshes}

The calculation code is used to modelize the distribution of electric field in a human body when illuminated by a RF source. The source is a dipole antenna functioning at 27.12 $\mathrm{MHz}$. The external boundary is a parallelepiped box, located close to the body (Fig. 6.b).

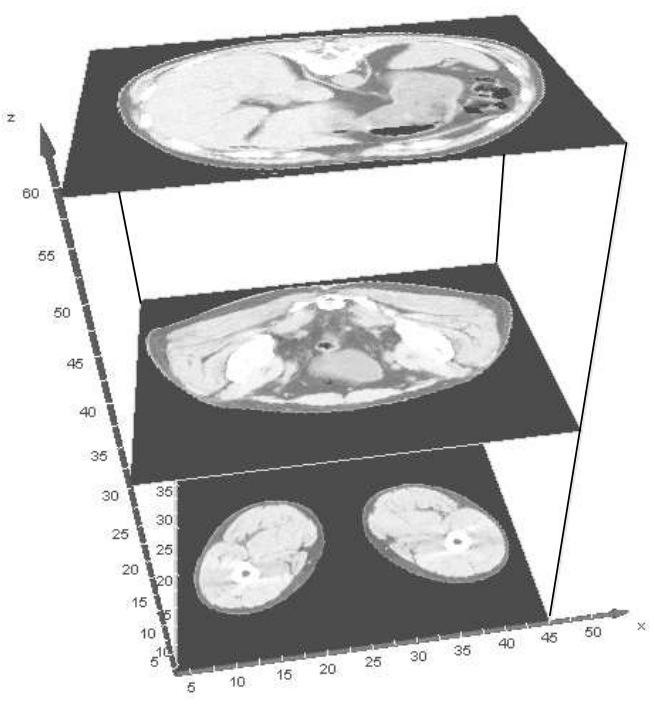

(6.a)

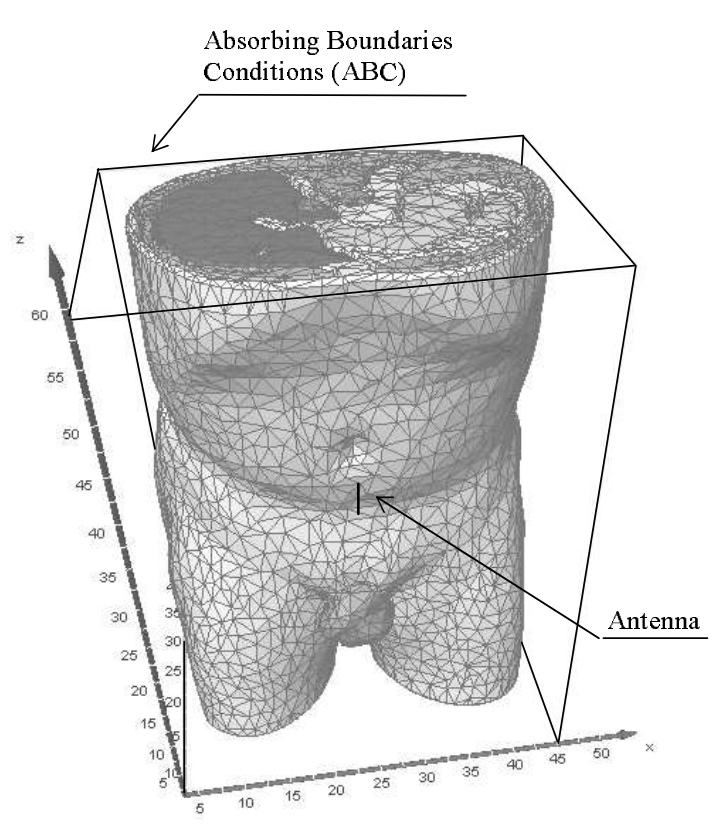

(6.b)

Fig. 6. Geometry of the model device (6.b) coming from CT scans (6.a).

\subsection{Geometry}

The mesh is obtained from 59 CT scans, allowing to take into account the real shape of the patient (Fig. 6.a). It is obtained using the Amira package [25]. It includes 33181 nodes, 182650 tetrahedral elements and 221606 degrees of freedom.

\subsection{Properties of media}

This geometry includes 12 different media. The properties of these tissues are given in Table 5 for the frequency 27.12 $\mathrm{MHz}[23,24]$. The main factor having influence on the values of the conductivity and the permittivity of the tissues is the water content [26]. Therefore, tissues can be divided into those with high water content, such as eye, muscle, skin, liver and kidney, and those with low water content, such as fat and bone.

Table 5. Electromagnetic properties of the different media for the frequency $27.12 \mathrm{MHz}$. 
(Fig. 11.a). The patient is exposed to an electric field with only one RF source (Fig. 11.b and Fig. 11.c) and then with two RF sources (Fig. 11.d). It is clearly shown that the use of two antennas changes largely the distribution of electric field in the $x$-section. So, by optimizing the location and the source values of the antennas, one can easily imagine to focus the radiation on the tumour.
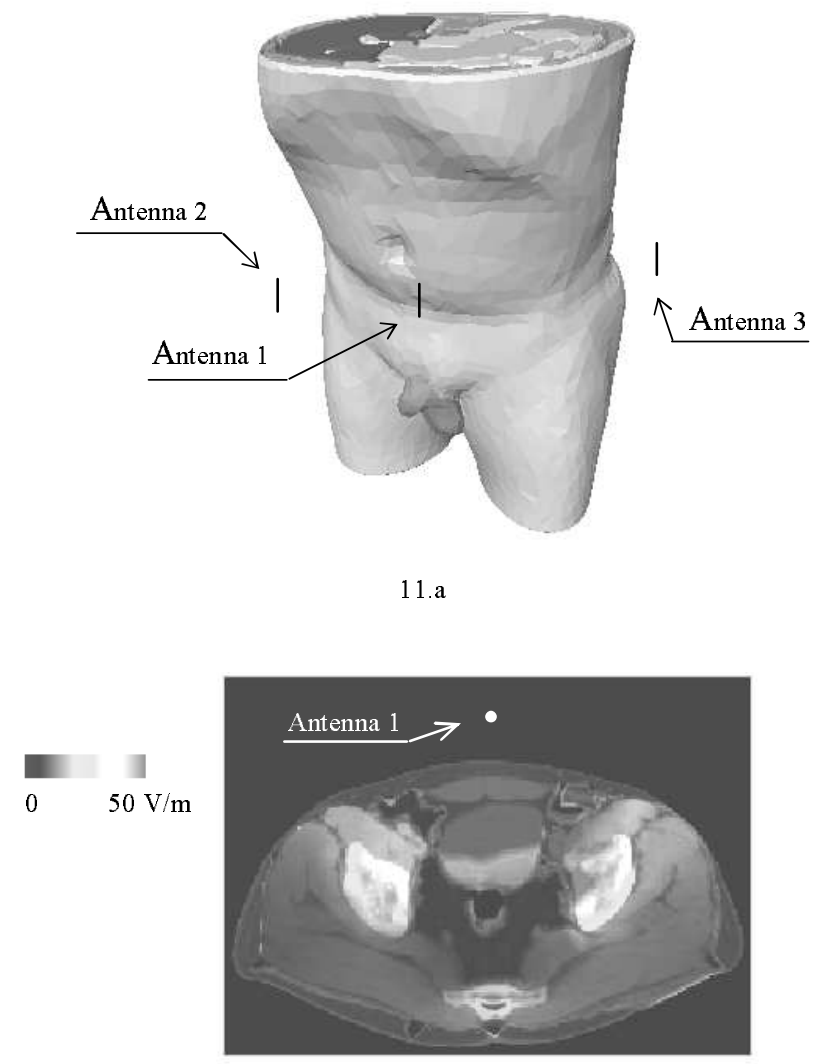

11.b

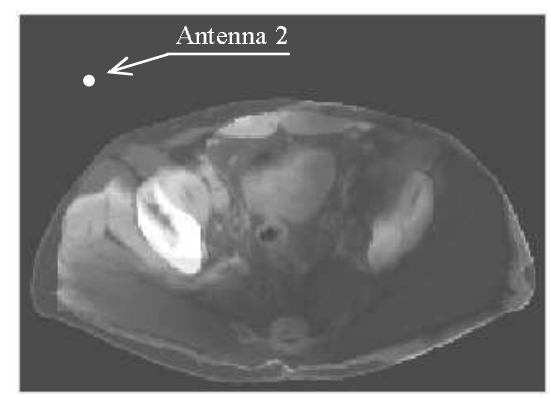

11.c

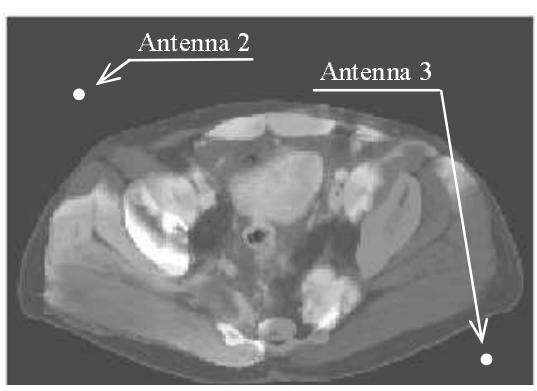

Fig. 11. Calculated electric field distribution on a section $(z=30 \mathrm{~cm})$ with one antenna $(11 . \mathrm{b}-11 . \mathrm{c})$ and with two antennas (11.d).

\section{Conclusions and perspectives}

A 3-dimensional model based on the FE method implemented with edge elements has been developed. The numerical results have been compared with experimental measurements and show a good agreement. The developed model is able to handle with heterogeneous structures and with real human organs meshes assembled from CT scans.

The final objective is the modelling of several applicators functioning simultaneously, to obtain the best possible focalization of the heat in the desired area [27]. The FE formulation will then be coupled to a genetic optimization algorithm. This will allow to optimize both the location of the

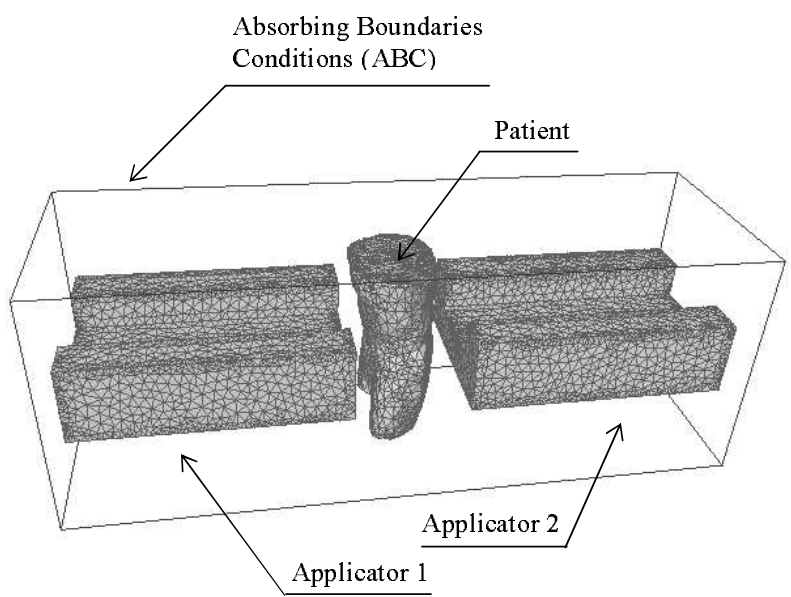

applicators and the values of the current sources (amplitude and phase) in order to improve the distribution of temperature in the zone processed. Another aspect of the study is the modelling of other types of sources. As example, the figure 12 shows the mesh of an hyperthemia devices with two applicators. The coupling between the waveguides and the patient is achieved by a bolus (not represented on the figure).

Fig. 12. Modelling of two applicators and the patient.

Figure 13 shows the results obtained with the configuration including the two waveguides operating at 27.12 MHz, the bolus and the patient. The sources (modules and phases) are not optimized, there is no phase shift between the two sources and their amplitudes are the same. The 
results are presented in term of magnitude of the electric field.

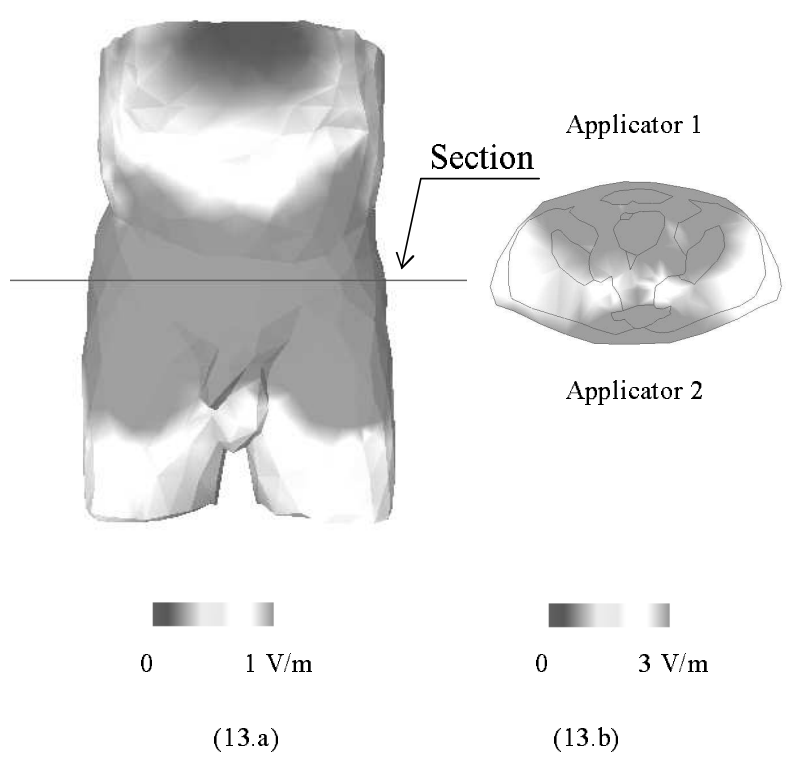

Fig. 13. Calculated electric field on the muscle and the fat of the patient (13.a) and on a section (13.b).

This calculation tool, allowing to obtain the electric field, SAR distribution and including computerized optimization procedure, will be used for the hyperthermia treatment planing performed with $\mathrm{RF}$ phased array systems.

\section{References}

1. J. LANG, B. ERDMANN, M. SEEBASS, IEEE Trans. Biomedical engineering 46, 1129 (1999).

2. O.S. NIELSEN, M. HORSMAN, J. OVERGAARD, European Journal of Cancer 37, 1587 (2001).

3. C.K. CHOU, IEEE Trans. Instrumentation and Measurement 37, 547 (1998).

4. A.M. TUMEH, M.F. ISKANDER, IEEE Trans. Microwave Theory and Techniques 37, 1126 (1989).

5. S. RATNAJEEVAN, H. HOOLE, V. SATHIASEELAN, A. TSENG, IEEE Trans. Magnetics 26, 1011 (1990).

6. J. WIERSMA, R.A.M. VAN MAARSEVEEN, J.D.P. VAN DIJK, Int. J. Hyperthermia 18, 73 (2002).
7. J. ZEE, J.N. PEER-VALSTAR, P.J. RIETVELD, L. GRAFF, G.C. RHOON, Int. J. Radiation Oncology Biol. Phys. 40, 1205 (1998).

8. J.A. SHAW, C.H. DURNEY, D.A CHRISTENSEN, IEEE Trans. Biomedical Engineering 38, 861 (1991).

9. P.C CHERRY, M.F ISKANDER, IEEE Trans. Microwave Theory and Techniques 40, 1692 (1992).

10. N.M. POTHECARY, C.J. RAILTON, IEEE MTT-S Digest, 1151 (1993).

11. C.E. REUTER, A. TAFLOVE, V. SATHIASEELAN, IEEE Trans. Microwave Theory and Techniques 46, 313 (1998).

12. Y. KANAI, T. TSUKAMOTO, T. KASHIWA, IEEE Trans. Magnetics 32, 1661 (1996).

13. D.R LYNCH, K.D PAULSEN, J.W STROHBEHN, Journal of Computational Physics 58, 246 (1985).

14. A. SEKKAK, V.N. KANELLOPOULOS, L. PICHON, A. RAZEK, IEEE Trans. Magnetics 31, 1865 (1995).

15. C.A. BALANIS, Advanced engineering electromagnetics (John Wiley \& Sons, Inc., New York, 1989), p. 150.

16. B. ENGQUIST, A. MAJDA, Math. Comp., 31, 629 (1977).

17. J.C. NEDELEC, Numer. Math. 35, 315 (1980).

18. J.P. WEBB, IEEE Trans. Magnetics 29, 1460 (1993).

19. S.T. CLEGG, K.A. MURPHY, W.T. JOINES, G. RINE, T.V. Samulski, IEEE Trans. Microwave Theory and Techniques 42, 1984 (1994).

20. C. NIDERST, Ph.D. thesis, université Paul Sabatier de Toulouse, 1997.

21. A. VERA-HERNANDEZ, Ph.D. thesis, institut national polytechnique de Lorraine, 1999.

22. W.E. BOYSE, G.N. MINERBO, K.D. PAULSEN, D.R. LYNCH, IEEE Trans. Magnetics 29, 1333 (1993).

23. S. GABRIEL, R.W. LAU, C. GABRIEL, Phys. Med. Biol. 41, 2251 (1996).

24. S. GABRIEL, R.W. LAU, C. GABRIEL, Phys. Med. Biol. 41, 2271 (1996).

25. Template Graphics Software inc., www.amiravis.com.

26. C.K. CHOU, H. BASSEN, J. OSEPCHUK, Q. BALZANO, R. PETERSEN, M. MELTZ, R. CLEVELAND, Bioelectromagnetics 17, 195 (1996).

27. A. BOAG, Y. LEVIATAN, A. BOAG, IEEE Trans. Biomedical engineering 40, 946 (1993). 